\title{
Design of a Web System for the administrative control of the medical records in a Health Center
}

\author{
Alexi Delgado ${ }^{1}$, Alarcón AlcaldeRebeca Sarai ${ }^{2}$ \\ ${ }^{1}$ Mining EngineeringSection, Pontificia Universidad Católica del Perú, Lima-Peru, kdelgadov@pucp.edu.pe \\ ${ }^{2}$ Systems EngineeringProgram, Universidad de Ciencias y Humanidades, Lima-Peru, rebalarcona@uch.pe
}

\begin{abstract}
Many healthcare facilities do not have a system for monitoring patient medical records, which leads to one of the biggest conflicts for nurses and patients, as there is a great deal of information loss and data redundancy. To prevent such problems it is necessary to implement a web system, which organizes the medical records of each patient in a dynamic and continuous way. This work was carried out with the Scrum methodology, which is characterized by carrying out small and large projects in a given time, resulting in an efficient system. In this case study the four Sprint were determined, which are intended to be carried out by modules. The results of this application would have the diagnostics in an immediate time. The results obtained could help doctors, nurses, patients and mainly health centers to better diagnose the patient, optimizing the service and the control of information.
\end{abstract}

Key words :Diagnostic, Medical records, Scrum, Sprint, Web system.

\section{INTRODUCTION}

Nowadays, there are problems in some health facilities as most personnel continue to record patients on paper, which implies a great loss of data on each of them and redundancy, making it difficult to recreate a new record considering the waiting time for the process [1], [2]. The reason for this is that several hospitals do not have a web system where they can make their records without losing any information [3]. Thus, the management and control becomes scarce since they do not have the relevant and updated data, making the time delay relative; for this reason, a system is sought to be implemented where there is better control while reducing the time to fill in the paper record [4].

To carry out this system, the Scrum methodology will be implemented as it provides us in detail the steps to perform the administration and control of the development process of this software and conduct it in a short time. Likewise, it has an iterative model together with the incremental model for successive constructions of the application [5][6]. This methodology is developed in 5 phases, it begins with the first sprint or called Product Backlog in which user stories will be made, gathering all the requirements together with the user to obtain good results in the application to be developed [7]. The second phase is about the Sprint Backlog, where the one who leads the Scrum team, delegates the tasks to the developers and to have a better performance, through an organization tool the leader delegates an increase per developer giving an acceptable time to make the increase [8]. As a third phase, Daily Scrum is mentioned, in which meetings will be held together with the client, these meetings will be held from time to time to see the details of the software to develop [9]. On the fourth phase, the Sprint Review asks us to verify the requirements in detail and implement new ideas, even for a smooth operation. Finally in the fifth Retrospective Sprint, we can contribute with the client to implement new requirements or improve some modifications if needed [10].

To develop the application the steps of the methodology will be followed, in the first Sprint, will be needed to verify 6 stories of main users to have knowledge and notions of treating the web system [11]. Phase 2 is developed in 4 sprints, which are the incremental models already mentioned above. In Phase 3, the schedules of the meetings with the team and the client are made [12]. Finally, in phases 4 and 5, the last details of the application are made, new user stories will be developed for better control of the medical records.

The aim is to design and implement a web system for the registration of medical records, which will be carried out to have better control of the management control of employees, patients and expedite the registration process by $65 \%$ and thus avoid long queues that are made for consultations and delivery of medical records improving the efficiency and effectiveness in the medical health care facility.

The structure of the present paper has been divided into sections. Section 2 will detail the methodology and tools used. This is followed by section 3 , which seeks to detail the methodology applied in the case study. In section 4 the results are discussed by analyzing the application and methodology. Finally, in section 5 the conclusions are presented.

\section{METHODOLOGY}

This section will explain in detail the architecture of the SCRUM methodology to optimize and streamline the process of administrative control of medical records. The Web System is developed with the PHP language accompanied by the JavaScript language using the base manager of MYSQL data, likewise it is designed in the Balsamiq tool in order to 
simulate the necessary interfaces.

The MVC architecture model will be applied to develop the project, in which the model will have a representation of data handled by the system concerning the business logic. The view will be friendly and easy to use to maintain the constant interaction. Finally, in the controller, it will manage the flow of information and transform said information to adapt to the queries made by the user.

\subsection{SCRUM}

It is an interactive incremental framework for developing projects or applications dynamically. Has a structure of development cycles known as "Sprint", which may also be understood as a group of activities that are structured to be fulfilled in a given time[13][14]. The Scrum methodology provides a personalized way to work on various projects, which have a variety of requirements and thus have many advantages when selecting the requirements to develop within the Sprint[15]. Has the following phases [16]:

\section{A. Phase I. Product Backlog}

In this phase the requirements of the most relevant processes of the project will be gathered together with the client to form the design of the web system. Likewise, the administrators or users who will use this system and the use cases that will be made will also be identified.

\section{B. Phase II. Sprint Backlog}

In the second phase, the project leader is sought, such leader delegates to the team the increases that were made as follows: one of the software developers will be in charge of the design of the page, other one will make the programming of the system, finally the user will make the cards of the patients and the clinical personnel to have the administrative control of the patients.

\section{Phase III. Daily Scrum}

A third phase is the meetings that will be held weekly to supervise that the project is carried out as the client requested; these meetings will be carried out together with the client and new information will be obtained for the development of the system, thus having more reliability in the development of the same.

\section{Phase IV. Sprint Review}

In this phase the new user stories or new requirements are presented to improve the system, it is completed by making the latest revisions to the system.

\section{E. Phase V. Sprint Retrospective}

Lastly new improvements for the administrative control web system for a hospital are identified.

Figure 1 shows the steps that will be performed in the SCRUM methodology to expedite the administrative control process.

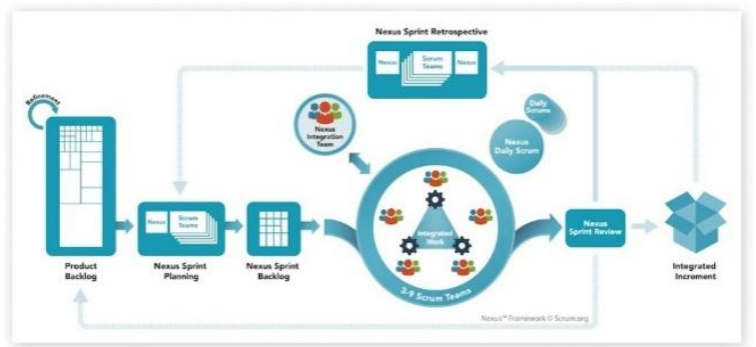

Figure 1: Scrum methodology of the Web System for administrative control of medical records for the health sector[17]

\subsection{PHP}

It is a kind of typical server-side scripting language used for the creation and execution of dynamic web page design on the server[18][19].

\subsection{JavaScript}

This language can be incorporated into various web pages, it is independent and object-oriented [20].

\subsection{Balsamiq}

It is an effective instrument for prototyping systems or applications to be developed as quickly as possible with an easy-to-use interface; it is one of the most frequently used tools for building prototypes, as it has many components that can be adapted to the application to be developed [13][21].

\subsection{MVC}

It is composed of the model, display and controller layer. In the model layer the data is worked, usually placed in a database with CRUD. On the other hand, in the display layer the interfaces are made. Finally, in the controller layer the bond between the views and the models is formed[22], [23].

\section{APPLICATION}

An incremental model was used for the application, which is based on the collection of the descriptive data through the people related to the process itself, i.e. those who work in the hospital. For this purpose, it was necessary to identify the processes, with the aim of accelerating these with the system to be implemented. The processes to be optimized should be plotted on a graph [5], [24], as shown in Figure 2.

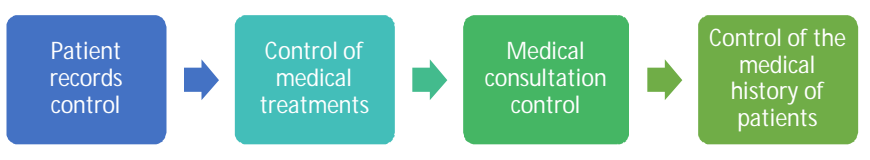

Figure 2: Incremental model of administrative control of medical records

\section{A. First Increment. Patient records control}

In this first increase, all the information of the people who undergo treatments will be collected, all this information will be stored in a MySQL database. This information will include the records of the patient's health problems, the disease they 
suffer from, the treatment they are undergoing with their respective schedules, among others; this way the doctor will closely follow the evolution of the treatment.

\section{B. Second Increment. Control of medical treatments}

In this increase, all patients will be registered not only with their patient ID and full names, but also with their photos, as well as the information of the doctor and nurse who attended them at the health center.

\section{Third Increment. Medical consultation control}

In the control of the consultations, the administrator will register the consultations of the patients. With these records, the administrator will have better control of the attendance of the patient at the health center for proper treatment.

\section{Fourth Increment. Control of the medical history of patients}

Once the previous steps have been carried out correctly, the fourth increment will deal with the control of the data entered to avoid possible errors that may have arisen throughout the process.

After defining the increments, the steps of the Scrum methodology will be carried out.

\subsection{Phase I. Product Backlog}

In this case, the client is the administrator of a health center, which is in difficulty because of problems with patient records and attending physicians. Consequently, the requirements requested by the client for the present project regarding the design and objective of the implementation of a web system for the administrative control of medical records can be seen in Table 1:

Table 1: User stories of the web system for the administrative control of clinical histories

\begin{tabular}{|c|c|}
\hline $\mathbf{N}^{\circ}$ & USER STORIES \\
\hline 1 & $\begin{array}{l}\text { As a director, I need to register all patients in the } \\
\text { database to have better control of patient treatments } \\
\text { and thus be able to make a good diagnosis. }\end{array}$ \\
\hline 2 & $\begin{array}{l}\text { As a doctor, I need to be able to make a complete } \\
\text { record of all the treatments and medications of each of } \\
\text { the patients registered. }\end{array}$ \\
\hline 3 & $\begin{array}{l}\text { As a director, I need the medical consultations that } \\
\text { were carried out in order to have better control and to } \\
\text { have daily reports of the medical consultations carried } \\
\text { out. }\end{array}$ \\
\hline 4 & $\begin{array}{l}\text { As a director, I need to have all the medical records } \\
\text { and personal data of each one of them to have better } \\
\text { control of the history to finally have a report of the } \\
\text { diseases that are frequented in certain districts. }\end{array}$ \\
\hline 5 & $\begin{array}{l}\text { As a director, I need the medication history to have } \\
\text { better control of the quantities sold during the day, } \\
\text { week, etc. }\end{array}$ \\
\hline 6 & $\begin{array}{l}\text { As a doctor, I need access to evaluate the medical } \\
\text { appointments to make daily reports of the amounts of } \\
\text { daily consultations that are performed. }\end{array}$ \\
\hline
\end{tabular}

\subsection{Phase II. Sprint Backlog}

\section{A. Sprint 1:Patient records control}

This module will be carried out by modeling the design and construction, in which doctors will be able to enter through a login, being located in the patient records section, in order for them to record the patient data.

\section{B. Sprint 2: Control of medical treatments}

Once the patient is selected, the type of treatment according to the patient needs is chosen.

\section{Sprint 3. Medical consultation control}

Once the treatment has been registered, the next appointment will be scheduled.

\section{Sprint 4: Control of the medical history of patients}

This module will record the details of the treatments of each of the patients, as well as personal information.

\subsection{Phase III. Daily Scrum}

Meetings will be scheduled every two weeks so the software developer has more time to detail the program. In addition, these meetings will help the customer to make new contributions to the system and to observe the progress of the requirements. To do this, we will use the Trello tool for the purpose of delegating tasks and getting a better visualization of the progress.

In Figure 3, you can see the organization of the project delegated by the SCRUM team leader, who presented a deliverable for each software developer so that the project and design are developed optimally in the shortest possible time.

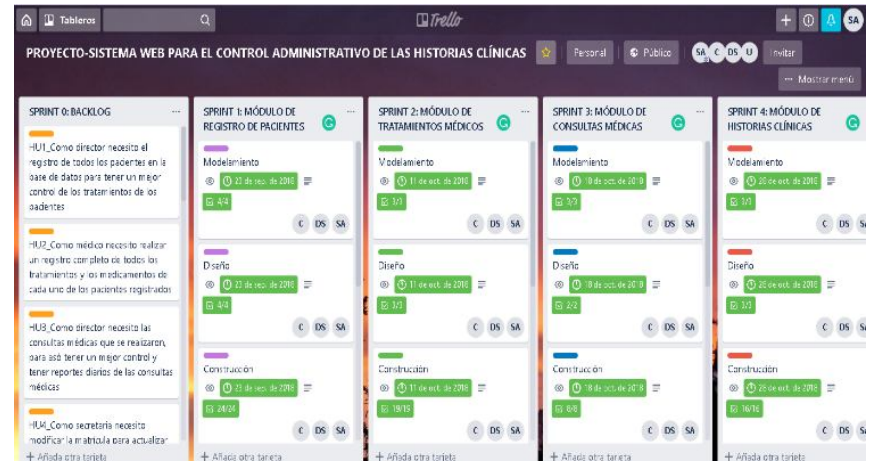

Figure 3: Trello Board of the Web System for the administrative control of medical records

\subsection{Phase IV. Sprint Review}

In this phase the last submission will be made to the customer, who reviews it and proposes new user stories if needed. In this case, the web system design will be carried out as shown in Figure 4. 


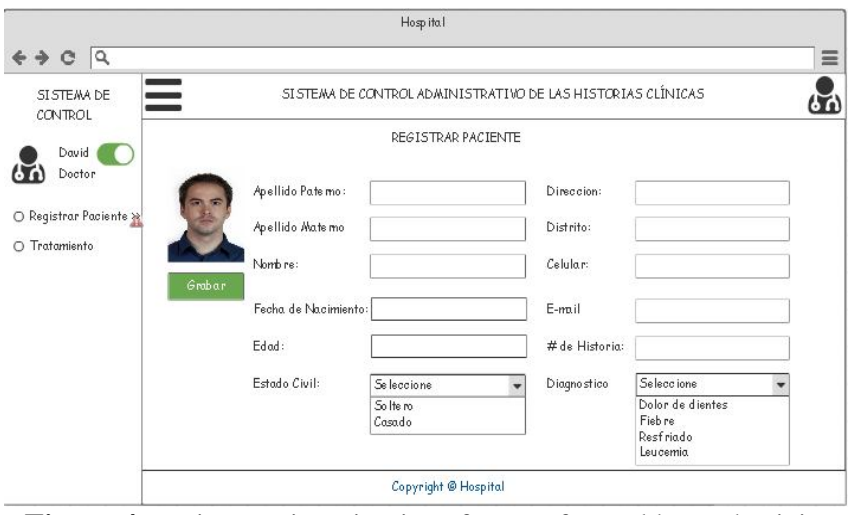

Figure 4: Patient registration interface performed by a Physician

In Figure 5, you can see one of the administrator's interfaces, only the administrator will be able to make the reports as well as the person that the administrator delegates his account.

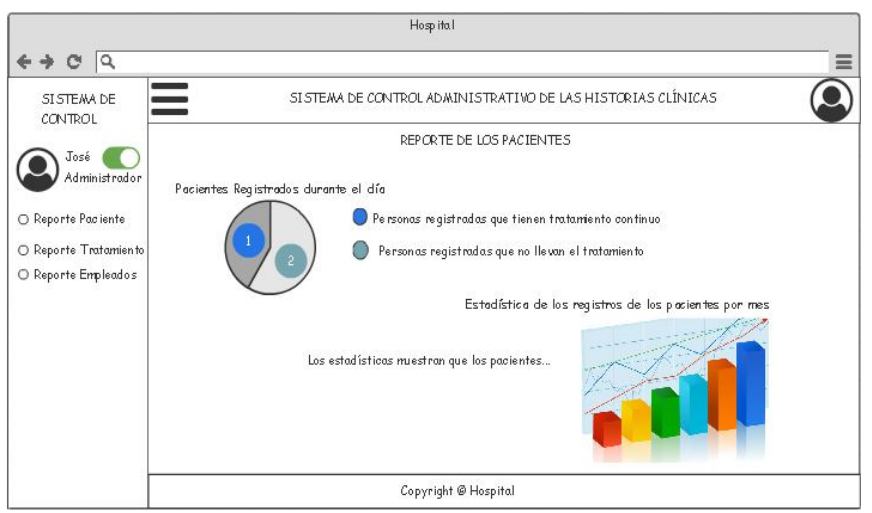

Figure 5: The interface of patient reports per day and month by the administrator

Figure 6 shows the design of the interface of the consultations that a will be carried out by a nurse.

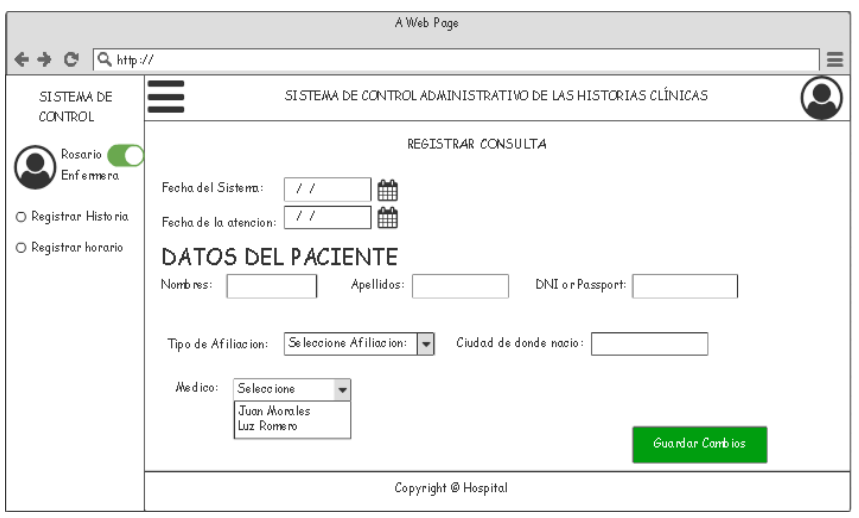

Figure 6: Query interface made by a nurse

\subsection{Phase V. Sprint Retrospective}

In this phase, new interfaces will be designed for the interaction between the user and the system, so that they can view their information or make inquiries if needed.

\section{RESULTS AND DISCUSSION}

\subsection{About the Case Study}

In the case study, the design of the medical records with the necessary fields of the patients was carried out [25], as shown in Figure 7.

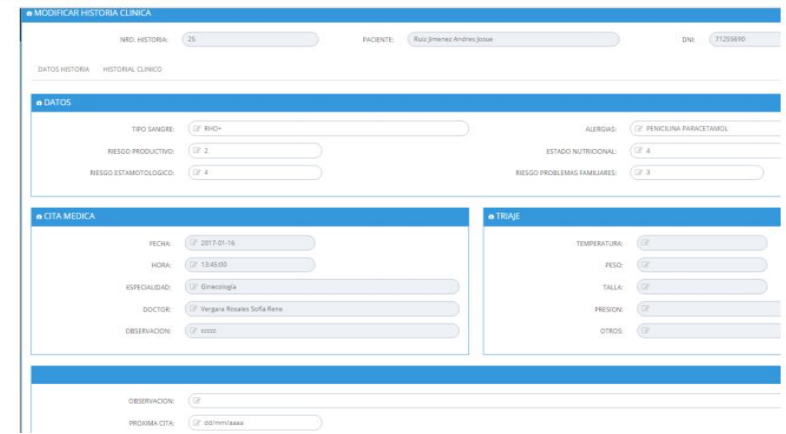

Figure7: Screen of the expected medical history record [25]

In this article [25], we show the steps to implement the application that optimizes the medical records process [26]. In this paper it is shown that the application of Clinical Histories will be developed with the languages PHP, JavaScript together with the database MySQL. However, there is a methodology and other languages to make an application of the Clinical Histories. In the role of an adaptive web information system based on web services, the application can also be made with the Android Studio application [27].

\subsection{About the Methodology}

The methodology implemented in this work was the SCRUM methodology, which facilitated monthly deliveries and helped us to regularly manage client expectations based on tangible results. This will benefit improved productivity and service quality, as well as alignment between the client and the software development team.

On the other hand, some of the advantages are its flexibility and adaptability as well as the fact that it turns out to be a transparent process for those involved, with anticipated results [28]. However, it is detected that there is a high level of stress of the Scrum team members [29], [30].

In comparison with other feasible methodologies to implement a web system, the RUP and UML methodology can be used, which have had optimistic results; nonetheless, the SCRUM methodology surpasses those mentioned since it is a faster approach [31].

\section{CONCLUSION}

The application proved to be effective in terms of patient history consultations, which generates possible solutions and automatic reports of individual patient histories and diagnoses made in a given time.

The methodology used was able to show which were the most relevant reports and made statistics of the most common diseases to generate possible solutions in the future ensuring a 
better service.

With this methodology, new research topics can be implemented, such as the preventive diagnosis of diseases, either applied with other programming languages. It can also be implemented in mobile applications with QR code, allowing patients to make appointments in their nearest health centers.

\section{REFERENCES}

[1] E. T. Sianturi, "No TitleE $\Lambda$ ENH," $A \gamma \alpha \eta$, vol. 8, no. 5, p. 55, 2019.

[2] Y. Shikunov, Y. Stepchenkov, D. Khilko, and D. Shikunov, "Data redundancy problems in data-flow computing and solutions implemented on the recurrent architecture," in Proceedings of the 2017 IEEE Russia Section Young Researchers in Electrical and Electronic Engineering Conference, ElConRus 2017, 2017, pp. 335-338.

https://doi.org/10.1109/EIConRus.2017.7910559

[3] S. Petcy Carolin and M. Somasundaram, "Data loss protection and data security using agents for cloud environment," 2016 Int. Conf. Comput. Technol. Intell. Data Eng. ICCTIDE 2016, 2016.

[4] E. P. D. E. Ingenier et al., "Universidad nacional de piura."

[5] A. Srivastava, S. Bhardwaj, and S. Saraswat, "SCRUM model for agile methodology," in Proceeding - IEEE International Conference on Computing, Communication and Automation, ICCCA 2017, 2017, vol. 2017-January, pp. 864-869. https://doi.org/10.1109/CCAA.2017.8229928

[6] V. Bax, W. Francesconi, and A. Delgado, "Land-use conflicts between biodiversity conservation and extractive industries in the Peruvian Andes," $J$. Environ. Manage., vol. 232, pp. 1028-1036, Feb. 2019.

[7] E. A. Engum, Z. Racheva, and M. Daneva, "Sprint planning with a digital aid tool: Lessons learnt," Conf. Proc. EUROMICRO, no. i, pp. 259-262, 2009.

[8] T. Besker, A. Martini, and J. Bosch, "Technical Debt Triage in Backlog Management," 2019 IEEE/ACM Int. Conf. Tech. Debt, pp. 13-22, 2019.

https://doi.org/10.1109/TechDebt.2019.00010

[9] M. is S. Cohn, "What is Scrum mountaingoatsoftware," 2015.

[10] K. Pathak and A. Saha, "Review of Agile Software Development Methodologies," Int. J. Adv. Res. Comput. Sci. Softw. Eng., vol. 3, no. 2, p. 2277, 2013.

[11] M. Paasivaara, C. Lassenius, and V. T. Heikkilä, "Inter-team coordination in large-scale globally distributed scrum: Do scrum-of-scrums really work?," Int. Symp. Empir. Softw. Eng. Meas., pp. 235-238, 2012.

[12] E. Hossain, M. Ali Babar, and H. Y. Paik, "Using scrum in global software development: A systematic literature review," Proc. - 2009 4th IEEE Int. Conf. Glob. Softw. Eng. ICGSE 2009, pp. 175-184, 2009. https://doi.org/10.1109/ICGSE.2009.25

[13] C. Mendoza-Santos and A. Delgado, "Web application design for the control process of public schools," Int. J. Emerg. Trends Eng. Res., vol. 8, no. 4, pp. 1289-1294, Apr. 2020. https://doi.org/10.30534/ijeter/2020/57842020

[14] A. Delgado and I. Romero, "Applying the Grey Systems Theory to Assess Social Impact from an Energy Project," in 2018 IEEE XXV International Conference on Electronics, Electrical Engineering and Computing (INTERCON), 2018, pp. 1-4.

[15] A. Mundra, S. Misra, and C. A. Dhawale, "Practical scrum-scrum team: Way to produce successful and quality software," in Proceedings of the 2013 13th International Conference on Computational Science and Its Applications, ICCSA 2013, 2013, pp. $119-123$.

[16] "Los 5 pasos del Scrum Master.".

[17] "Scrum.org libera una nuevas actualizaciones de Nexus.".

[18] H. Huang, J. Bi, and X. Yang, "Networked monitoring system based on embedded dynamic web," Proc. World Congr. Intell. Control Autom., pp. 208-213, 2011.

https://doi.org/10.1109/WCICA.2011.5970730

[19] A. Delgado and H. Flor, "Selection of the best air purifier system to urban houses using AHP," in 2017 CHILEAN Conference on Electrical, Electronics Engineering, Information and Communication Technologies, CHILECON 2017 - Proceedings, 2017, vol. 2017-Janua.

[20] A. Guha, C. Saftoiu, and S. Krishnamurthi, "The Essence of JavaScript The Need for Another JavaScript Semantics $\lambda$ JS : A Tractable Semantics for JavaScript," Essence (Downsview)., pp. 126-150, 2010.

[21] A. Delgado, P. Montellanos, and J. Llave, "Air quality level assessment in Lima city using the grey clustering method," in IEEE ICA-ACCA 2018 - IEEE International Conference on Automation/23rd Congress of the Chilean Association of Automatic Control: Towards an Industry 4.0 - Proceedings, 2019.

[22] A. Singh, P. Chawla, K. Singh, and A. K. Singh, "Formulating an MVC Framework for Web Development in Java," in Proceedings of the 2nd International Conference on Trends in Electronics and Informatics, ICOEI 2018, 2018, pp. 926-929.

[23] M. R. Mufid, A. Basofi, M. U. H. Al Rasyid, I. F. Rochimansyah, and A. Rokhim, "Design an MVC Model using Python for Flask Framework Development," in IES 2019 - International Electronics Symposium: The Role of Techno-Intelligence in Creating an Open Energy System Towards Energy Democracy, Proceedings, 2019, pp. 214-219.

[24] S. L. Olivares-Olivares, A. Garza-Cruz, and J. E. Valdez-García, "Etapas del modelo incremental de calidad: un análisis de las escuelas de medicina en México," Investig. en Educ. Médica, vol. 5, no. 17, pp. 24-31, 2016.

[25] L. A. Pairazaman Esteves and E. A. Vigo Escalante, 
Alexi Delgado et al., International Journal of Emerging Trends in Engineering Research, 8(6), June 2020,2739 - 2744

"Sistema De Información Web Para El Mejor Control Y Acceso A Las Historias Clínicas De Los Pacientes Del Centro De Salud Jequetepeque," Univ. Nac. Trujillo, 2017.

[26] S. Dalmiani, M. A. Morales, C. Carpeggiani, A. Macerata, and P. Marcheschi, "Electronic medical records optimize clinical data management in the outpatient cardiological clinic," Comput. Cardiol., vol. 30, no. Figure 2, pp. 681-684, 2003.

https://doi.org/10.1109/CIC.2003.1291247

[27] B. Soukkarieh and F. Sedes, "Towards an adaptive web information system based on web services," Proc. - 4th Int. Conf. Auton. Auton. Syst. ICAS 2008, pp. 272-277, 2008.

[28] A. Delgado and P. Condori, "Comparative Study of Methods to Improve Administrative Processes in a Organization," in 2018 Congreso Internacional de Innovacion y Tendencias en Ingenieria, CONIITI 2018 - Proceedings, 2018.

[29] S. Nootyaskool and P. Ounsrimuang, "Optimization algorithm using scrum process," in Proceedings International Conference on Machine Learning and Cybernetics, 2016, vol. 1, pp. 245-250.

[30] P. Ounsrimuang and S. Nootyaskool, "Introducing scrum process optimization," in Proceedings of 2017 International Conference on Machine Learning and Cybernetics, ICMLC 2017, 2017, vol. 1, pp. 175-181.

[31] L. Jin and X. Liang, "Modeling of instant messaging system based on RUP and UML," in Proceedings 2016 International Conference on Computational Intelligence and Applications, ICCIA 2016, 2016, pp. 61-66.

https://doi.org/10.1109/ICCIA.2016.18 